\title{
Supplementary Figures for A Physico-chemical Investigation into Major League Baseballs in the Era of Unprecedented Rise in Home Runs
}

Authors: Nathan Beals ${ }^{1,3}$, Liping Zhang ${ }^{1}$, Meng Law ${ }^{2}$, Darryl Hwang ${ }^{2}$, Jay Acharya ${ }^{2}$ and Soumitra Basu*1

\author{
AUTHOR ADDRESS \\ ${ }^{1}$ Department of Chemistry and Biochemistry, Kent State University, Kent, OH 44242 \\ ${ }^{2}$ Department of Radiology, Keck USC School of Medicine, USC Medical Center, 1520 San \\ Pablo Street, Suite L 1600, Los Angeles, CA 90033 \\ ${ }^{3}$ Department of Biochemistry and Molecular Pharmacology, New York University School of \\ Medicine, New York, NY, 10016
}




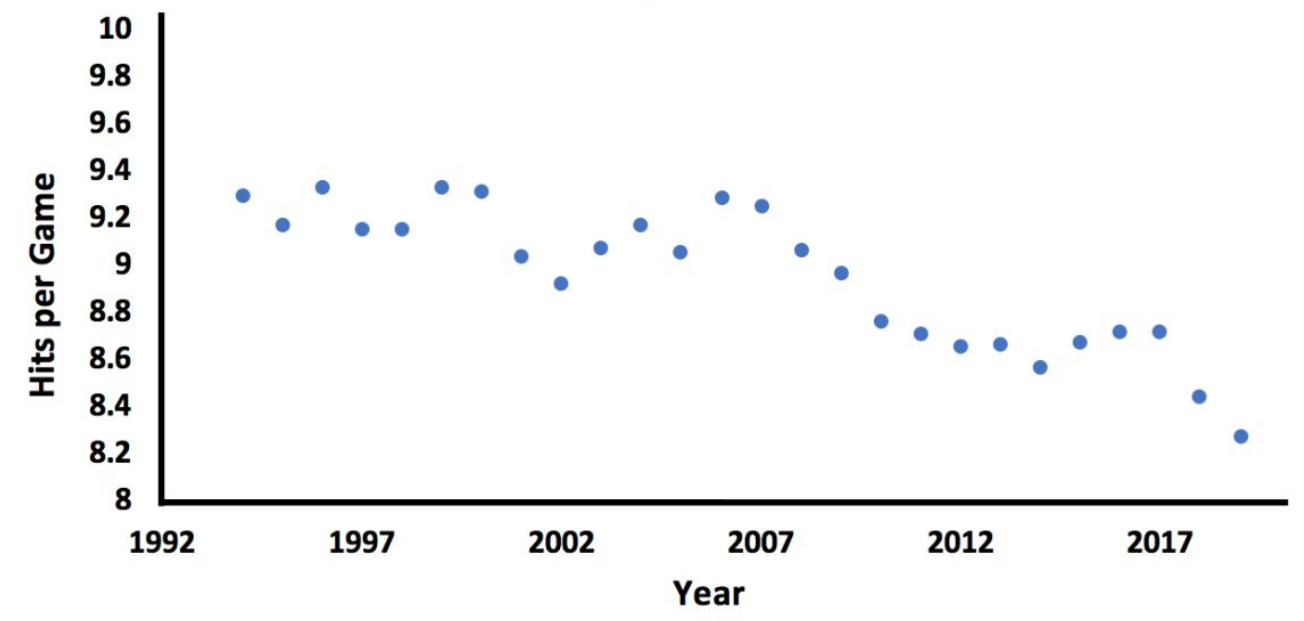

Figure S1. The number of hits per game has gone down. The annual hits per game were plotted from 1994-2019 to assess if other offensive production also saw similar trends as HR increases. 


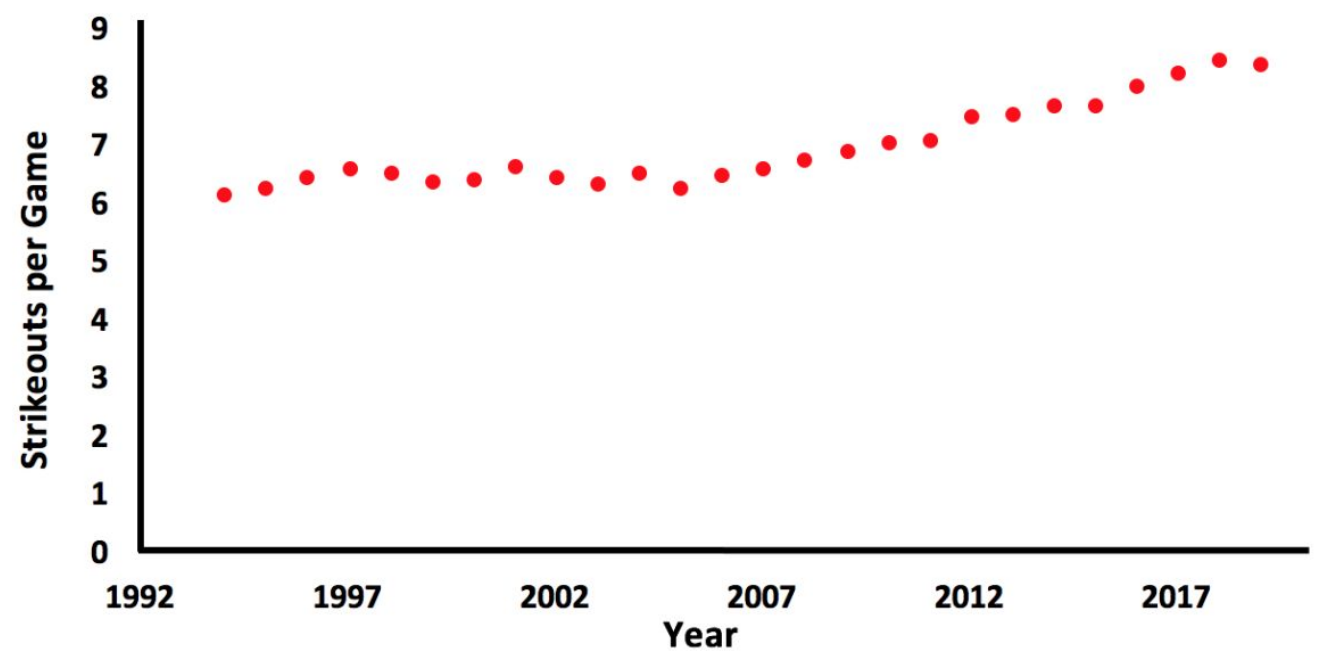

Figure S2. Strikeouts increased steadily over the last 20 years. From 1994-2019, strikeout rates per game have increased by almost 2.5 strikeouts. The largest difference this has caused is a decrease in fly ball and groundball outs as seen in Figure 2. 


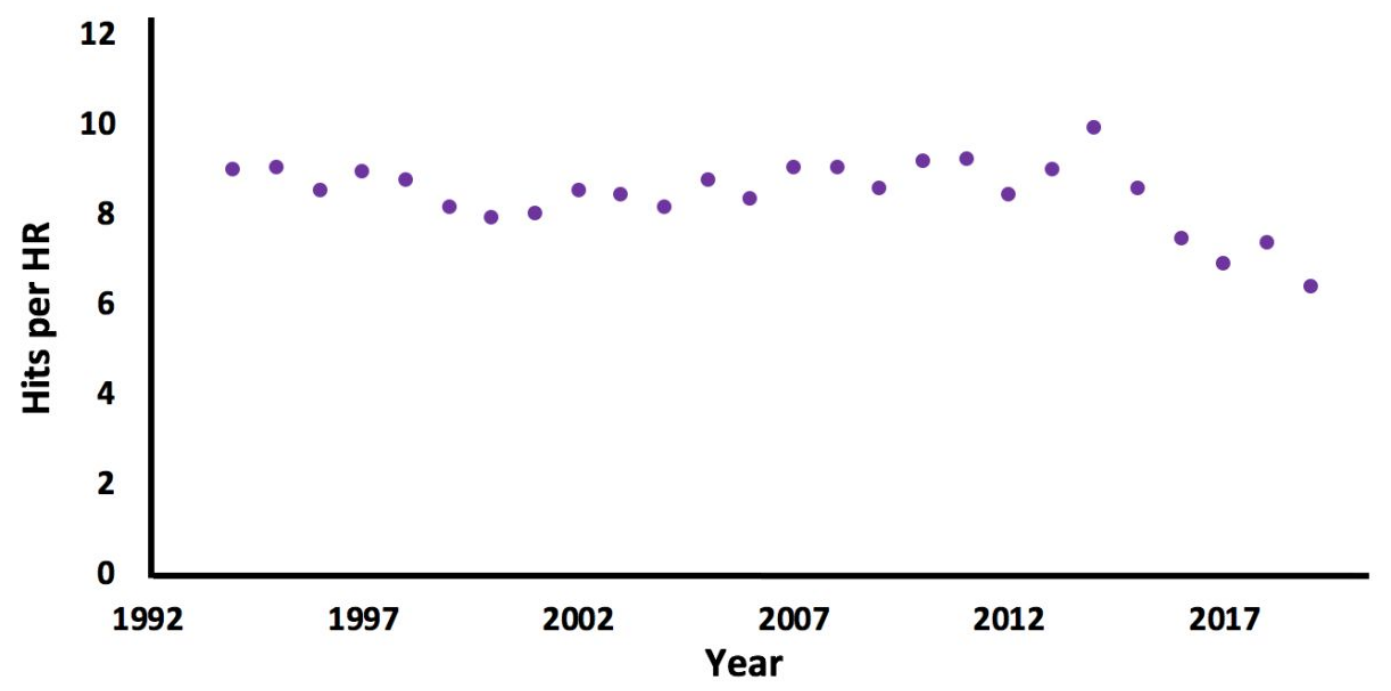

Figure S3. Every hit has over a $\mathbf{2 0 \%}$ increase of being a home run. MLB home runs were normalized to hits, indicating that the amount of hits between each home run hit has decreased by $15-22 \%$ in the 2016-2019 seasons. From 1994-2013, the deviation of Hits/HR did not exceed a 5\% difference from the average of 8.74 , outside of the peak of the PED era which saw a $10 \%$ decrease in 2000 . 


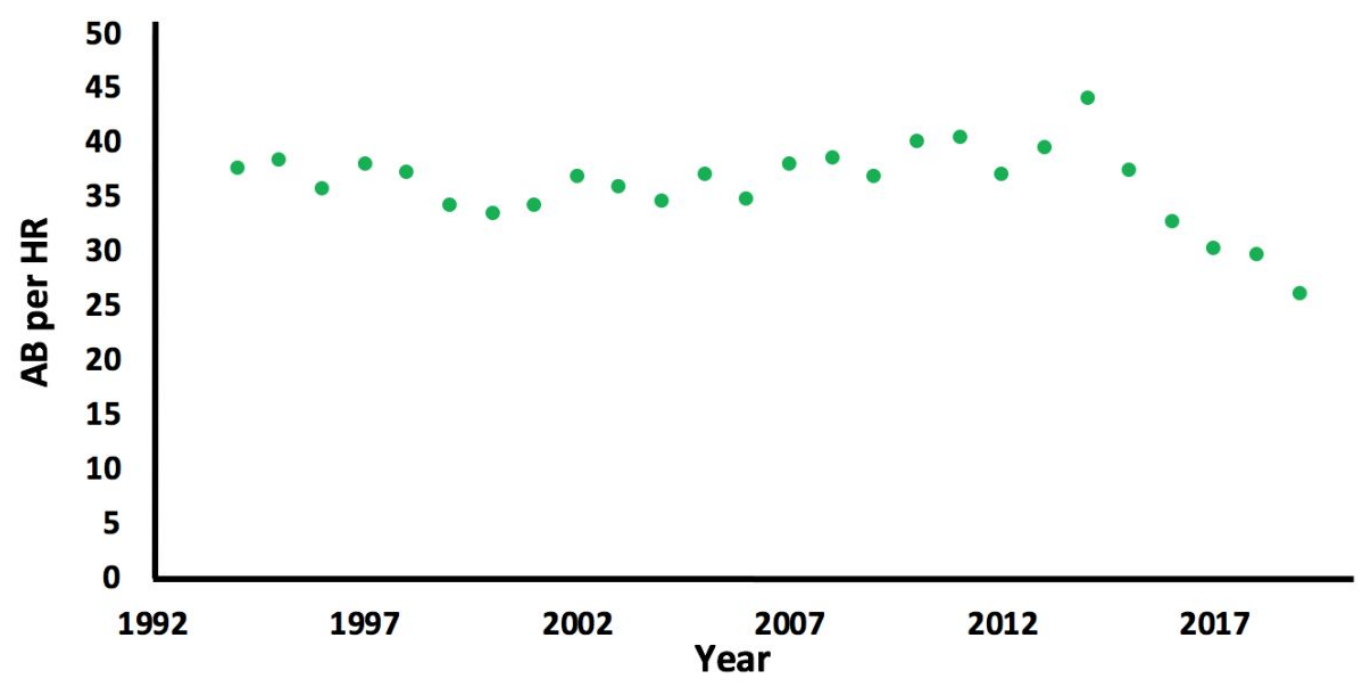

Figure S4. The at-bats between home runs have undergone a reduction. When normalized for the number of at-bats in a season compared to HRs hit, a decrease of $13-25 \%$ was observed in the 2016-2019 seasons. The average over the time period was 37.5 at-bats per HR. The low in that 24 years period outside of the most recent outliers of the 2016 and 2017 seasons, was a $10 \%$ decrease in 2000 


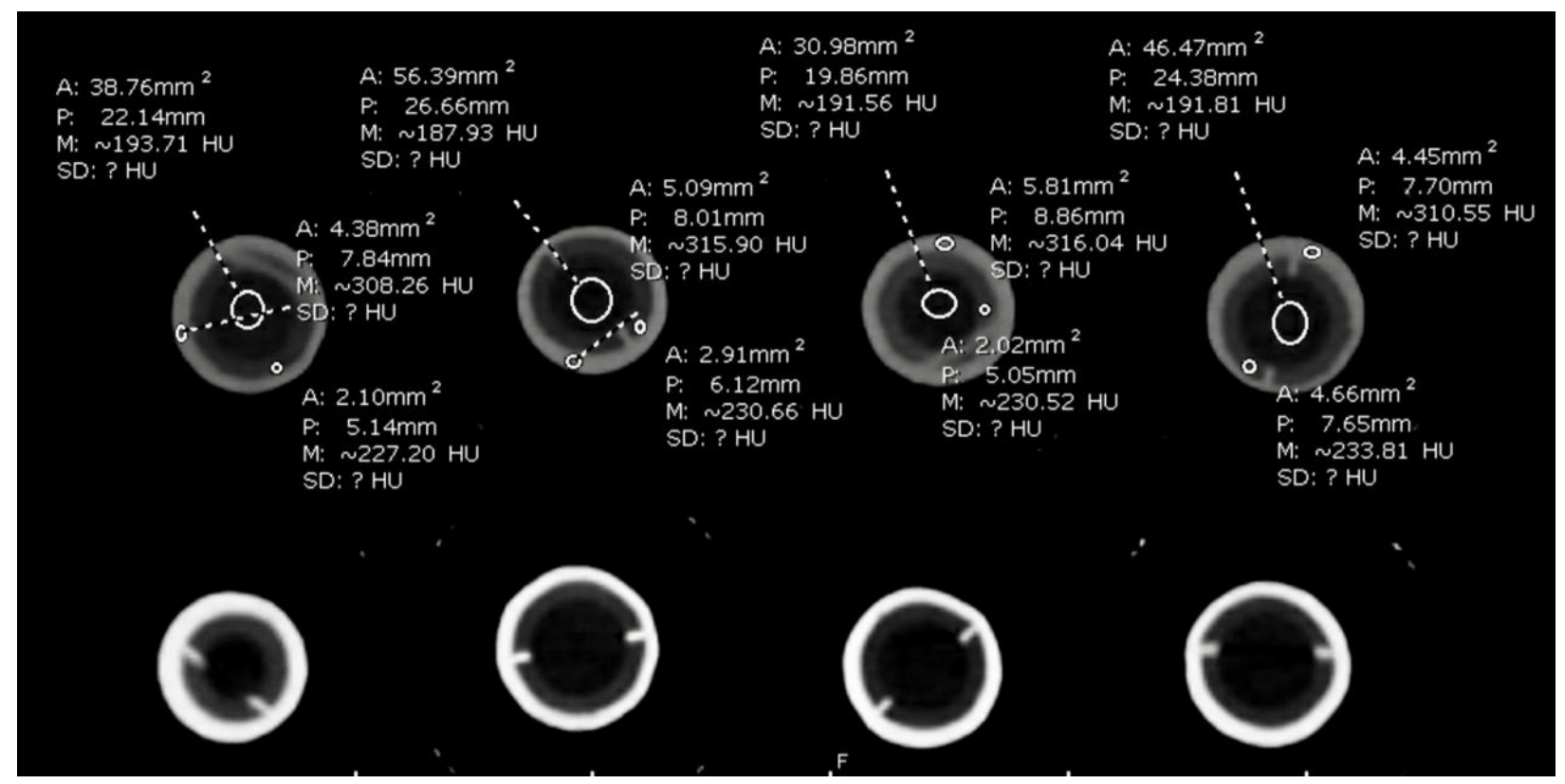

Figure S5. CT scans show a change in the radio-density of the inner pill of the baseball. MLB baseballs from 2014/ pre-ASG 2015 (Bottom) and 2017 (Top) were observed for changes in radiodensity using CT, as measured using Hounsfield Units. The 2017 game balls are highlighted with the HU of each part of the pill. 


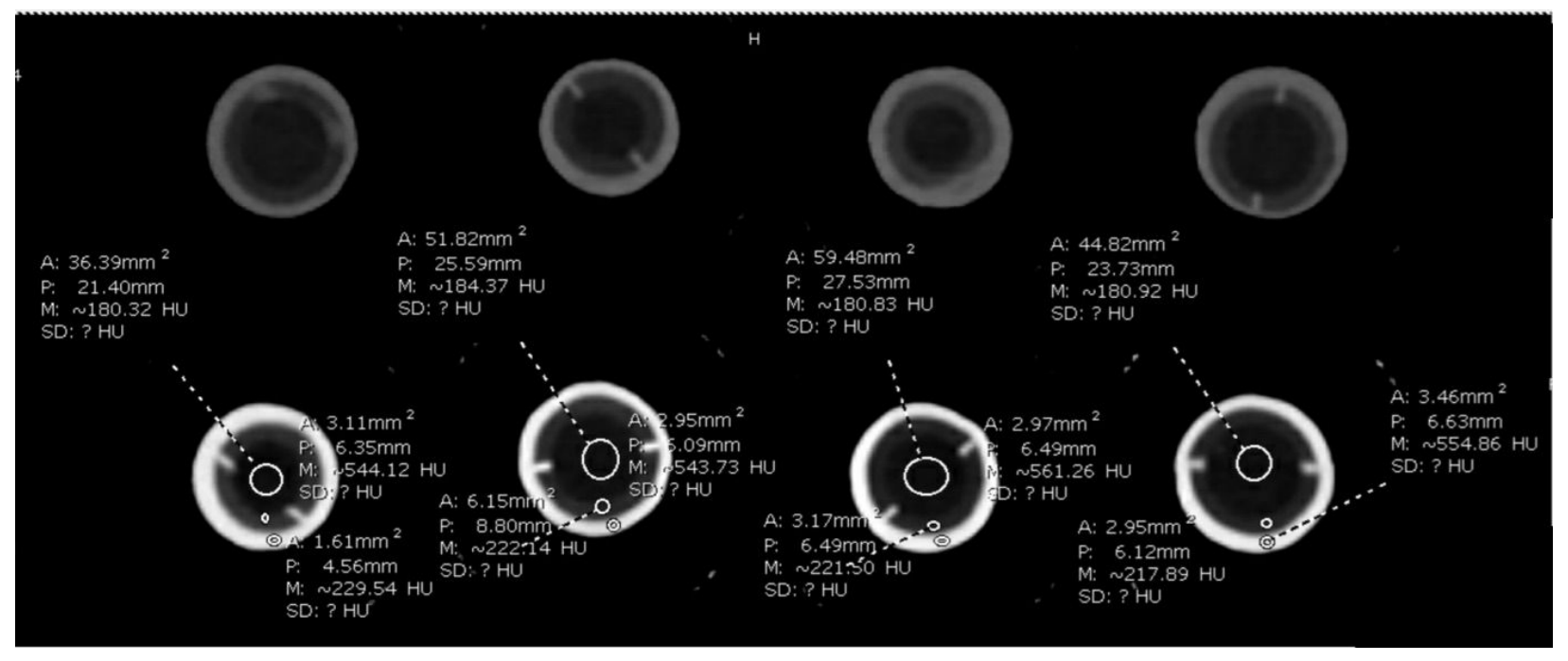

Figure S6. CT scans show a change in the radio-density of the inner pill of the baseball. MLB baseballs from 2014/ pre-ASG 2015 (Bottom) and 2017 (Top) were observed for changes in radiodensity using CT, as measured using Hounsfield Units. The 2014/ pre-ASG 2015 balls are highlighted with the HU of each part of the pill. 


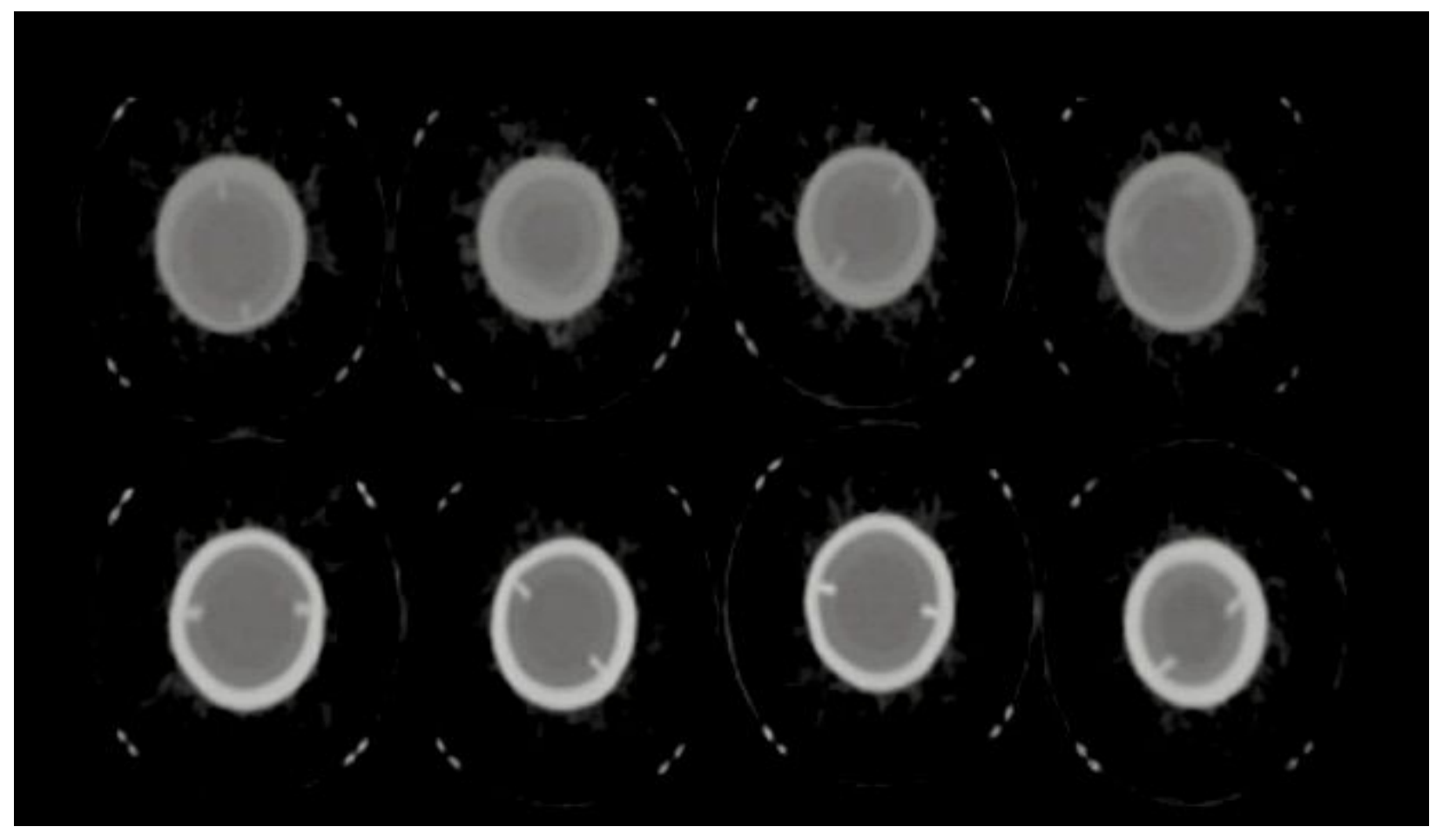

Figure S7. The raw images of MLB baseballs from 2014/ pre-ASG 2015 (Bottom) and 2017 (Top) observed using CT, as measured using Hounsfield Units. 


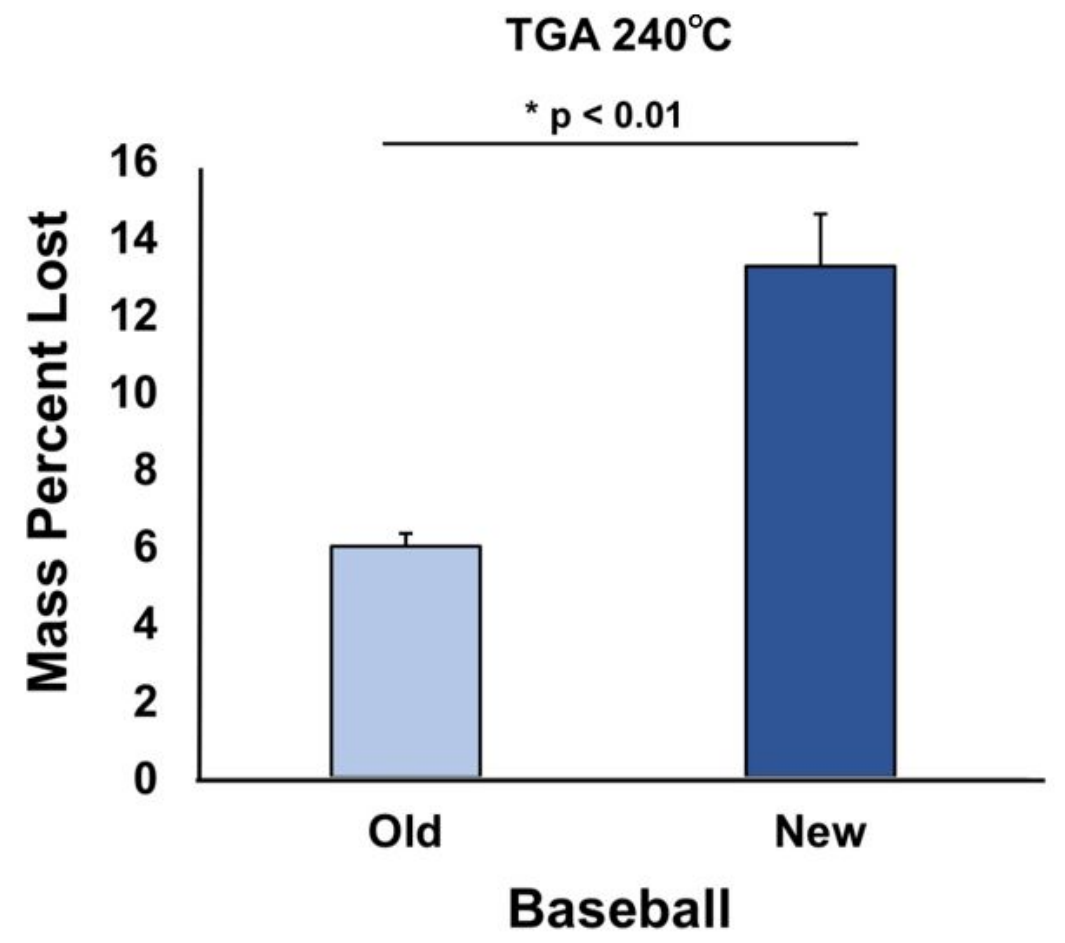

Figure S8. A $7 \%$ difference was found of in polymer composition at $240{ }^{\circ} \mathrm{C}$ of new and old baseballs. 


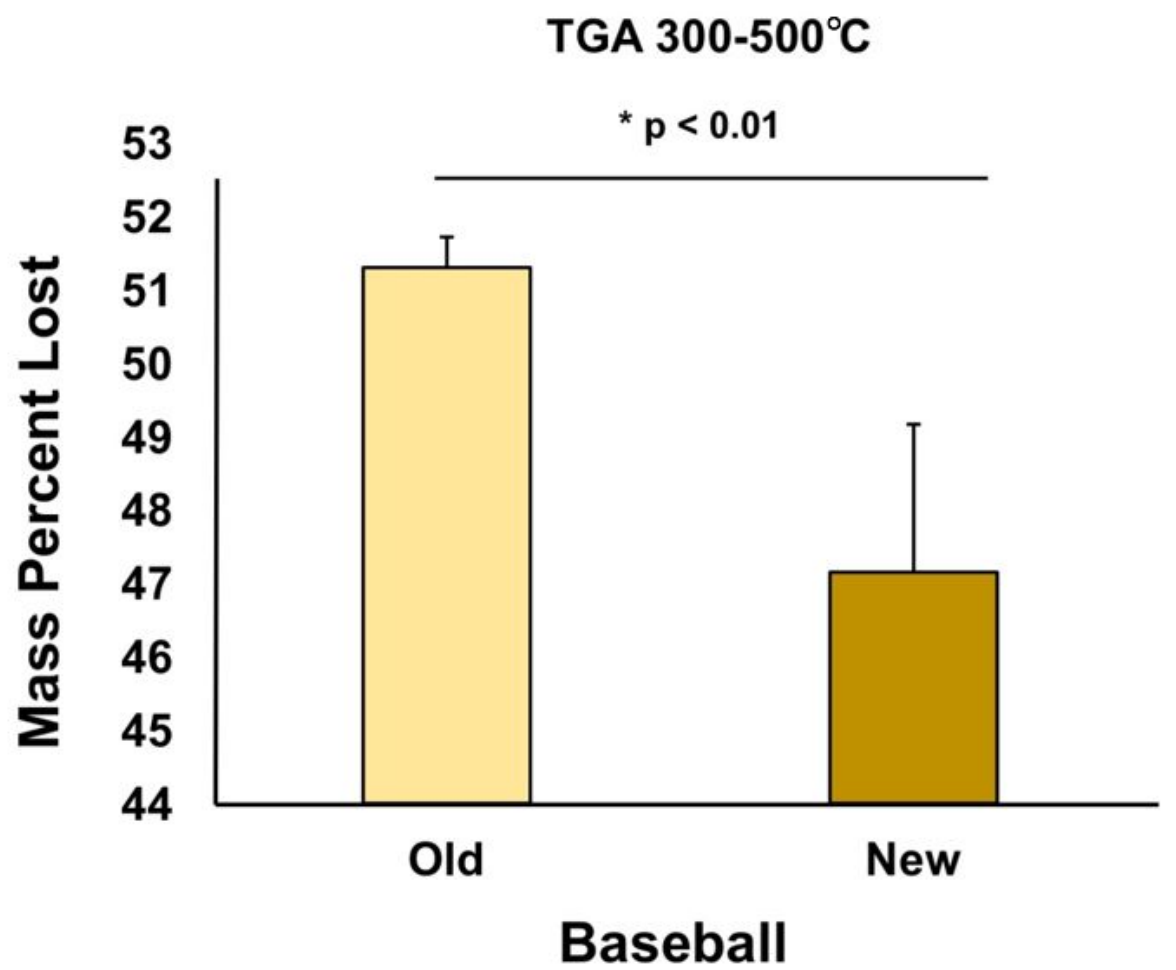

Figure S9. A 5\% difference was observed in the polymer composition between $300{ }^{\circ} \mathrm{C}$ and 500 ${ }^{\circ} \mathrm{C}$ of the new and old baseballs. 


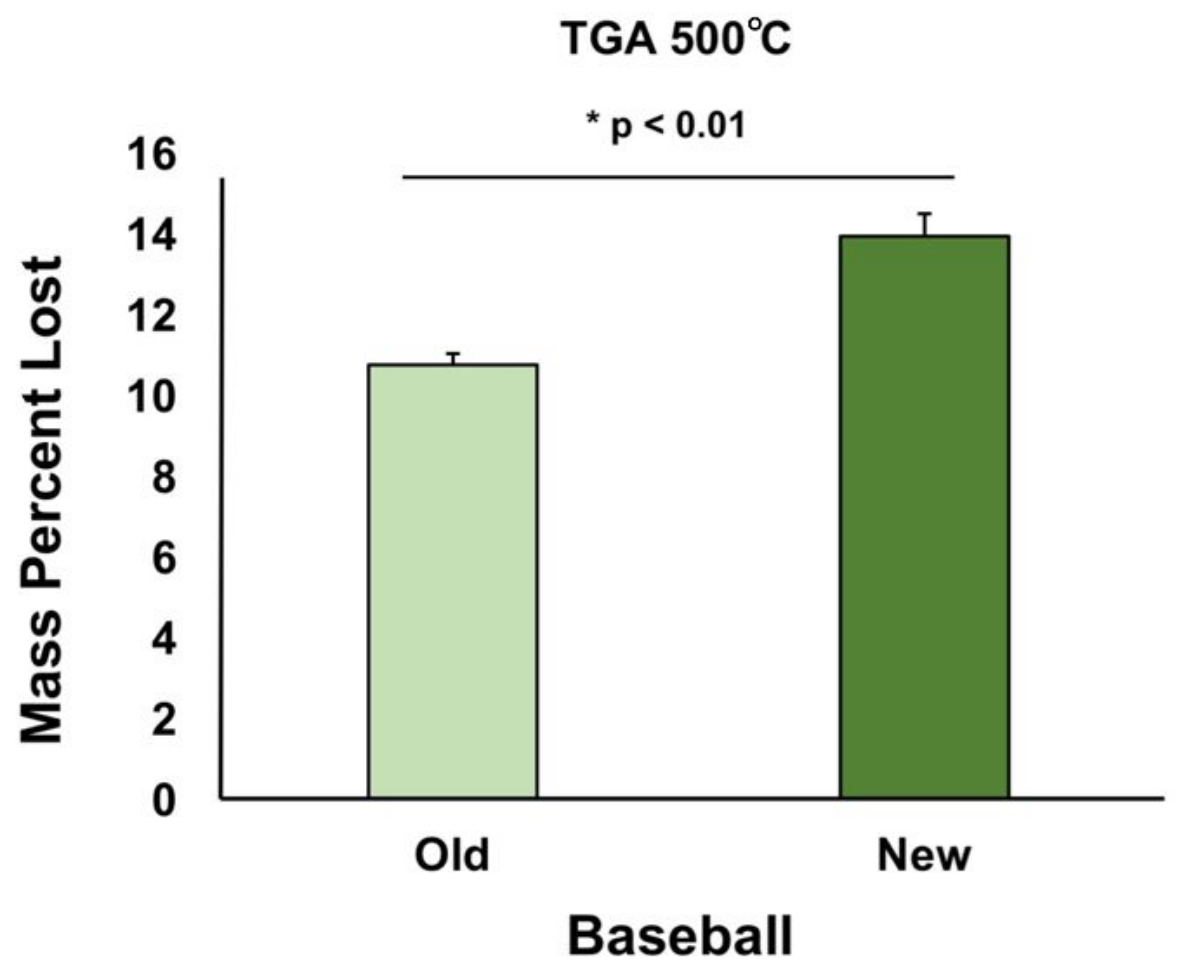

Figure S10. A 3\% difference was found of in polymer composition at $500{ }^{\circ} \mathrm{C}$ of new and old baseballs. 


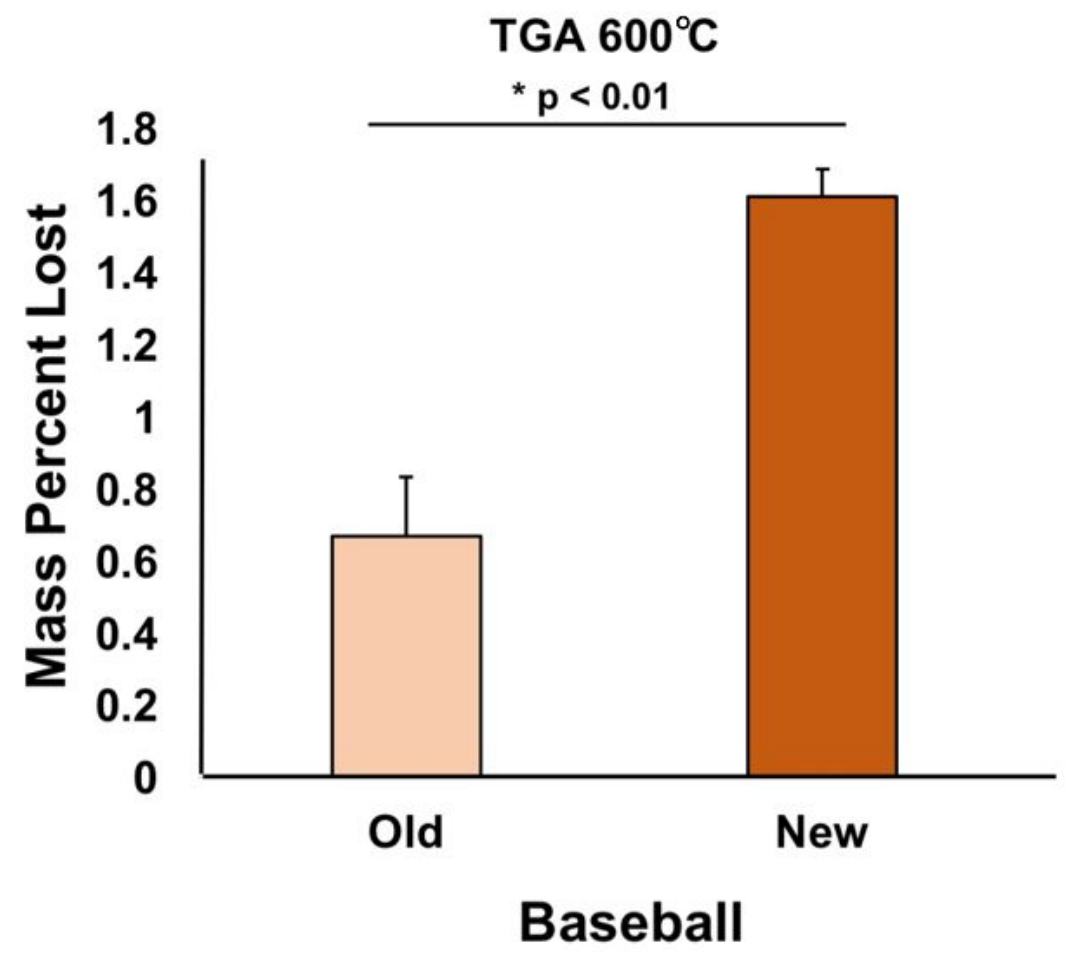

Figure S11. A 1\% difference was found of in polymer composition at $600{ }^{\circ} \mathrm{C}$ of new and old baseballs. 


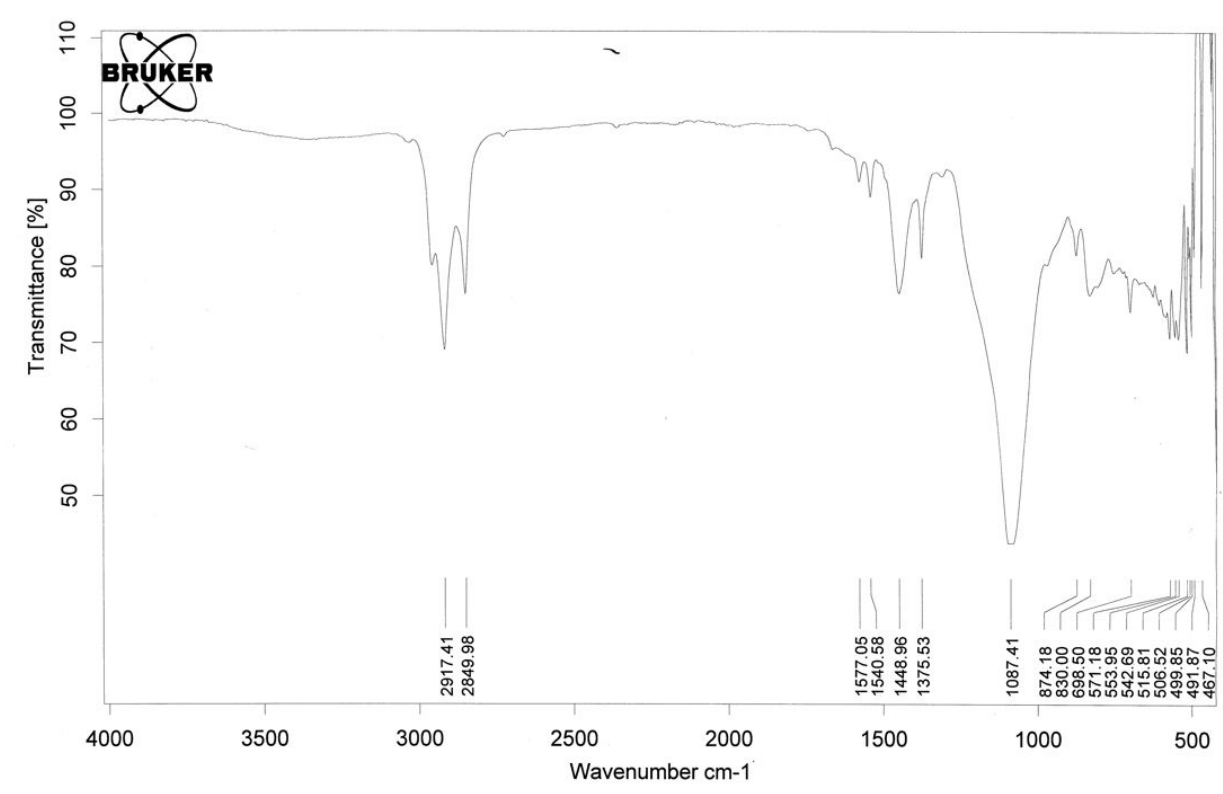

\begin{tabular}{|ll|l|}
\hline C:Inb201710824pink5.0 & pink5 & 8/24/2017 \\
\hline
\end{tabular}

Page 1/1

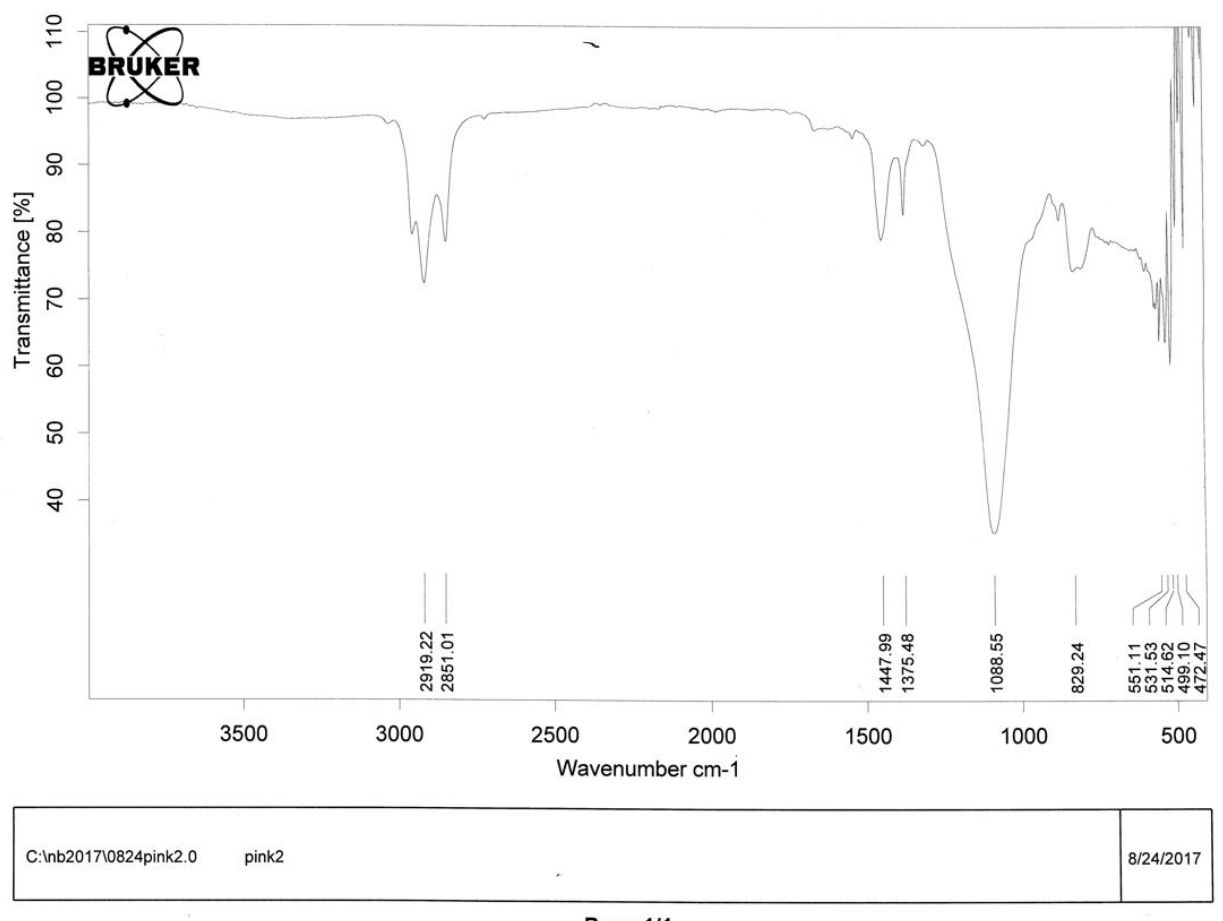

Page 1/1 
Figure S12. Infrared spectrometry showed no significant differences in the type of material used within the pink rubber of the pill. The spectra from both old (top) and new (bottom) balls are almost identical (outside a more intense peak at $1570 \mathrm{~nm}$ found in the old spectrum), illustrating that there is not a substantial difference in chemical composition between the old and new baseballs. 